\title{
Chile y sus museos comunitarios: reservas identitarias en escenarios de interculturalidad
}

\author{
Chile and its community museums: identity reserves in interculturality scenarios
}

\author{
Estela Adasme Calisto ${ }^{1}$ \\ Christian Quinteros Flores ${ }^{2}$
}

\section{Resumen}

En este artículo se han analizado los museos comunitarios de Chile, el aporte a la sustentabilidad social y a la identidad local de los territorios que representan estos espacios de conservación y exposición de artefactos tanto materiales como inmateriales, en escenarios de creciente interculturalidad. Se ha revisado el concepto de museo comunitario, distinguiéndolo conceptualmente de otros tipos de iniciativas similares, desde un enfoque de sustentabilidad. El estudio se ha realizado a partir del análisis descriptivo a nivel documental de siete casos de museos comunitarios registrados en la base de datos de la Dirección de Bibliotecas Archivos y Museos de Chile (DIBAM) donde se abordaron la totalidad existente, complementada esta información con dos experiencias de terreno. Esta investigación ha permitido conocer los aportes de este tipo de expresión cultural al reconocimiento de las identidades locales, lo que permite conservar el repertorio cultural de las comunidades donde se han insertado como sistemas de reproducción identitaria.

Palabras Clave: Desarrollo sustentable; comunidad; identidad; museo comunitario.

\section{Abstract}

In this article it has been analyzed the community museums from Chile, the contribution to social sustainability and the local identity of the territories that represent these conservation and exhibition spaces of both material and immaterial artifacts, in scenarios of increasing interculturality. The concept of community museum has been revised, distinguishing it conceptually from other types of similar initiatives, from a sustainability perspective. The study was carried out based on the documentary descriptive analysis of seven cases of community museums registered in the Directorate of Libraries Archives and Museums of Chile (DIBAM) database where the existing totality was addressed, complemented by two field experiences. This research has allowed to discern the contributions of this cultural expression type to

1 Master en Pedagogía en Educación Social, Trabajadora Social de la Universidad Santo Tomás. Correo: eadasmec@yahoo.es ORCID: https://orcid.org/oooo-0oo1-8839-3846

2 Master en Ciencia Política Universidad de Chile. Profesor de la Universidad Tecnológica de Chile Sede Pérez Rosales. Correo: cquinteros@Inacap.cl ORCID:https://orcid.org/oooo-0oo2-6145-9347

Recibido: 05/02/2018 Aprobado: 30/04/2018 
the recognition of local identities, which allows conserving the communities' cultural repertoire where they have been inserted as identity reproduction systems.

Keywords: Sustainable Development; community; identity; community museum.

\section{Introducción}

En Chile, el museo comunitario representa un tema emergente insuficientemente visibilizado, artefacto cultural con escasa exploración a nivel nacional. Estas Iniciativas culturales como los museos comunitarios pueden colaborar en la mantención y cuidado del patrimonio local fortaleciendo las buenas prácticas vecinales y el sentido cívico de la responsabilidad con el entorno. Permitiendo que los museos comunitarios en los asentamientos humanos sean inclusivos, seguros, resilientes y sostenibles. A su vez, pueden enmarcarse en el objetivo $\mathrm{N}^{\circ} 11$ de la Agenda de Desarrollo Sostenible 2030 de la Organización de Naciones Unidas establece la necesidad de generar en el mediano plazo ciudades sostenibles y lograr que los asentamientos humanos sean inclusivos, seguros, resilientes y sostenibles.

Por ello, el presente trabajo, pretende aportar preliminarmente a la comunicación y visibilización de las incipientes experiencias que presenta nuestro país en la creación de museos comunitarios. La implementación de museos comunitarios es un fenómeno de expresión cultural reciente, quizás asociado a la emergencia de nuevas identidades o de formas colectivas de respuesta de contención al avasallador proceso de globalización e interculturalidad que ha experimentado la sociedad chilena. La generación de museos comunitarios adquiere alta valoración toda vez que está en directa relación con la conservación de prácticas sociales de una comunidad determinada, que no sólo está relacionado con la consideración de factores materiales, como espacios construidos, infraestructura comunitaria, sino que además incluye claves inmateriales, vinculadas a historias comunitarias, personajes, mitos populares, creencias, que han incidido en el desarrollo de los asentamientos humanos en el territorio, lo que a su vez permite rescatar el patrimonio comunitario a nivel colectivo, generando una mayor sustentabilidad cultural de los grupos humanos, estableciéndose los museos comunitarios como un puente con cierto grado de consenso entre el pasado y el futuro de una colectividad.

\section{Revisión de literatura}

\section{La Interculturalidad en Chile}

Hoy nuestra región y específicamente nuestro país atraviesan por procesos migratorios complejos que modifican la identidad cultural nacional. Los procesos de inmigración y de urbanización aceleradamente incorporan nuevos ciudadanos y dinámicas en nuestros territorios. Estos flujos producen procesos de aculturación donde se mezclan 


\section{CIENCIAS SOCIALES}

e intercambian una serie de aspectos no sólo materiales sino también simbólicos e ideales. América Latina y el Caribe, que históricamente fue un subcontinente receptor de inmigrantes, pasó a ser, a partir de la segunda mitad del siglo XX, una región de emigración. La búsqueda de mayores ingresos, servicios y oportunidades de vida, los conflictos sociales y políticos, las violaciones de los derechos humanos y desastres causados por fenómenos naturales han motivado diversos flujos migratorios internacionales en la región.

La fuerte urbanización de las ciudades concentra en un espacio más reducido las distintas identidades culturales que ahora conviven amenazando la homogeneidad y monoculturalidad. La rápida urbanización de la región ha llevado a una creciente concentración de población pobre en las ciudades, que se dirige allí en busca de oportunidades de empleo, servicios públicos y soluciones en materia de vivienda. Todos estos factores juntos imponen desafíos de enormes proporciones para los gobiernos locales y el gobierno central. Al mismo tiempo, el proceso de urbanización ha creado nuevas oportunidades para mejorar la calidad de vida en las ciudades, a través de una mayor productividad de las empresas y de los trabajadores, producto de las economías de escala y de la aglomeración, y de un mejor acceso a servicios para la población "Un entorno así requiere intervenciones específicas y complejas, que generalmente combinan la preservación y adaptación de edificios, espacios públicos y redes de servicios; para su realización son necesarios importantes recursos financieros y la participación de actores públicos y privados. Sin embargo, la rehabilitación de barrios históricos y, en general, la renovación y el desarrollo de las zonas urbanas centrales puede producir beneficios duraderos que atraigan tanto a inversionistas públicos como privados: los primeros para mejorar la identidad local y promover el desarrollo económico, y los segundos principalmente para utilizar edificios restaurados con fines comerciales o residenciales. Para el Banco Interamericano de Desarrollo, "este tipo de intervenciones ayuda a catalizar y aumentar el interés de los residentes urbanos por el valor patrimonial y social de los centros de las ciudades" (BID, 2000).

Identidad es el proceso por el cual los actores sociales construyen el sentido de su acción atendiendo a un atributo cultural (o conjunto articulado de atributos culturales) al que se da prioridad sobre otras fuentes posibles de sentido de la acción. El reforzamiento de las identidades culturales es el principio básico de organización social, seguridad personal y movilización política. En nuestro tiempo histórico, las identidades religiosas, nacionales, territoriales, étnicas y de género aparecen como principios fundamentales de auto-definición, cuyo desarrollo marca la dinámica de las sociedades y la política de forma. Para Castells (2003), la superación de las identidades, que era el gran proyecto histórico del racionalismo (liberal o marxista) ha sido superada por el renovado poder de la identidad. Junto a estas identidades fuertes, comunitarias, aparentemente fundadas en experiencia histórica y tradición cultural, hay también el surgimiento de identidades individuales, auto-construidas en torno a un proyecto personal, (identidad familiar, o individualismo familiar). Por otra parte, 
también emergen otros tipos de identidad como la identidad regional que se constituye en principio de recomposición social frente a la crisis del Estado-Nación o la identidad religiosa, fundamentalista o moderada, que se constituye como el principal principio alternativo de reconstrucción del sentido a escala planetaria. Los casos de movimientos sociales identitarios en el mundo plantean un rechazo explícito a la globalización y una denuncia del Estado, convertido en rehén de los flujos globales,

Por otro lado, la revisión de la literatura ha mostrado como en las relaciones interculturales, es decir, la situación en la que personas de diversas culturas entran en contacto, se activan una serie de procesos psicológicos y sociales que determinan la naturaleza y resultado de las mismas. De dichos procesos cabe destacar la generación de ansiedad causada por la situación de incertidumbre que sienten las personas al actuar o interactuar en contextos culturales no propios. De modo global, estos autores estiman que la integración intercultural es más fácil de lograr cuando los miembros de la cultura dominante aceptan que los grupos de la cultura no dominante mantengan su propia herencia cultural y cuando les estimulan y permiten tomar parte activa de la sociedad, estableciendo relaciones con ellos. Desde la perspectiva del grupo no dominante, la integración es más fácil, cuando sus miembros están interesados en mantener sus propias raíces e identidad cultural, al mismo tiempo que apoyan y refuerzan el establecimiento de relaciones con el grupo dominante. Cuando estas situaciones favorables a dicha integración no se den, la persona, individualmente, deberá hacer acopio de su propia competencia para lograr superar presiones y obstáculos tanto del grupo dominante como del grupo minoritario (Aneas Álvarez, M.A., 2005).

Nos estamos moviendo dentro de una sociedad multicultural globalizada en la que ya no hay lugar para una cultura uniforme y estática, sino que hemos de acostumbrarnos a vivir dentro de un mundo donde coexisten diferentes culturas y formas de pensar, que son el resultado de un intercambio continuo de ideas, pensamientos y comportamientos. Ahora bien, este fenómeno de la multiculturalidad, si bien nos ofrece nuevas posibilidades de enriquecimiento mutuo, no está exento también de posibles problemas y conflictos que pueden surgir entre los diferentes pueblos. La realidad multicultural de nuestra sociedad se enfrenta, según Bartolomé, M. (2004). Existen tres situaciones conflictivas:

a. La desigualdad como consecuencia de percibir la diferencia cultural como deficiencia y no como posibilidad de enriquecimiento.

b. La exclusión al no contar con un estatus legal de ciudadanos.

c. La violencia como condición de estas situaciones estructurales.

Por esa razón, los museos están llamados a valorar y favorecer la diversidad cultural como un elemento esencial para la sociedad en la que se han de tener en cuenta valores tan importantes como el diálogo y la aceptación de los demás basados en el pluralismo, la diferencia, la competencia y la creatividad. Solamente desde ellos pueden darse el 
encuentro, los intercambios y la reflexión, más aún si este se construye o proyecta desde una dimensión comunitaria de la convivencia social.

\section{La importancia de la participación de las comunidades en la construcción de sus espacios}

Las culturas locales son reproducidas permanentemente por sus habitantes formando parte de lo identitario de una comunidad, actuando como verdaderas fuerzas centrípetas. Sin embargo, esas costumbres, creencias, mitos, muchas veces no son reconocidas por los sistemas educativos formales e institucionales quedando expuestas a su posible desaparición frente a la inexistencia de personas claves que lo reproduzcan a través de la oralidad u otros medios similares. La expresión museológica en su sentido más amplio recopila, sistematiza y evidencia, el patrimonio arqueológico, material, intelectual y artístico de un determinado sistema social, monopolizando en este ejercicio las pautas y reglas culturales de ese territorio en sus expresiones legítimas y favorece la construcción de un ethos universal y estándar, que corre el riesgo de invisibilizar todas aquellas particularidades locales, generándose, puntos de desencuentros o distancia frente a la comunidad dado que se presenta una realidad que no se asimila como propia. Por ello resulta interesante preguntarse, ¿cuánto ayudaría la identificación de sistemas culturales propios al desarrollo de una comunidad?, ¿Cuánto contribuiría el rescate y la conservación de todas aquellas prácticas propias del barrio a la preservación de la identidad de ese lugar y al interés de sus habitantes por permanecer en él?

Para autores como Bourdieau (1999) y Foucault, los sistemas de poder monopolizan las creencias y establecen jerarquías entre ellas, lo que afecta significativamente la calidad de la integración comunitaria, ya que la construcciones de la propia identidad individual tiene su correlato en el contexto mediato de socialización y culturalización, es decir, en los ambientes comunitarios donde nos desarrollamos, lo cual entrega elementos explicativos de nuestra historia y la construcción de un devenir con sentido, que reconoce los esfuerzos de los antepasados en la construcción social de un territorio determinado.

Es así, como en la evolución histórica de la museología, existen hitos que responden a lo anterior, como el movimiento de la nueva museología que dista bastante de aquella noción estática/contemplativa y conservacionista de museo, pasando a un modelo museológico, dinámico/activo con una funcionalidad social/comunitaria, "que por sus características específicas parecería más adecuado para actuar a nivel de museo regional o museo de poblaciones medianas y pequeñas y que se relaciona con los valores culturales propios de una comunidad" (Resoluciones de la Mesa Redonda de Santiago de Chile, 1972). 


\section{Hacia una construcción conceptual de museo comunitario}

La literatura disponible no ayuda totalmente a definir con exactitud sobre lo que es un museo comunitario, como tampoco entrega un modelo en que se plantee su metodología, sus técnicas, entre otros aspectos constitutivos; sin embargo, es posible encontrar algunas ideas vinculadas con experiencias que ayudan a comprender la construcción semántica de esta temática. Camarena C. y Morales T. (2009, p. 15) señalan que:

Un museo comunitario es una herramienta para que la comunidad afirme la posesión física y simbólica de su patrimonio, a través de sus propias formas de organización. En estos espacios, los integrantes de la comunidad construyen autoconocimiento colectivo que propicia la reflexión, la crítica y la creatividad. Fortalece la identidad porque legitima la historia y los valores propios, proyectando la forma de vida de la comunidad hacia adentro y hacia afuera.

El museo comunitario fue concebido desde sus inicios como un espacio participativo, cuya premisa era conjugar las preocupaciones de las comunidades indígenas, rurales y urbanas para ofrecerles la oportunidad de reconocerse con su patrimonio cultural, para descubrir y afirmar su valor, investigarlo, resguardarlo y disfrutarlo, estimulando la generación de proyectos de desarrollo basados en un aprovechamiento adecuado de su propio patrimonio, y propiciando la creación de un terreno común en el que las comunidades pudieran encontrarse y apoyarse.

Por otra parte, la Red de Museos Comunitarios en su blog (http//www.museoscomunitarios.org), enumera una serie características que distinguirían a un museo comunitario de uno tradicional como por ejemplo que: La iniciativa nace de la comunidad, se desarrolla a través de la consulta comunitaria, cuenta historias con la visión propia, instancia organizada de la comunidad dirige el museo, responde a necesidades de la comunidad, fortalece la organización y la acción comunitaria, la comunidad es dueña del museo". Según esta agrupación algunas de las cualidades que debería tener un museo comunitario son las siguientes:

Un museo comunitario es creado por la misma comunidad, es un museo de la comunidad, no elaborado en su exterior para la comunidad; Es una herramienta para que la comunidad afirme la posesión física y simbólica de su patrimonio, a través de sus propias formas de organización; fortalece la memoria que alimenta sus aspiraciones de futuro; genera múltiples proyectos para mejorar la calidad de vida, ofreciendo capacitación para enfrentar diversas necesidades, fortaleciendo la cultura tradicional, desarrollando nuevas formas de expresión, impulsando la valorización del arte popular y generando turismo controlado por la comunidad; es un puente para el intercambio cultural con otras comunidades, que permite descubrir intereses 
comunes, forjar alianzas e integrar redes que fortalece cada comunidad participante a través de proyectos conjuntos.

Respecto de objetivos que persiguen, los museos comunitarios permiten:

a) Fortalecer la apropiación comunitaria del patrimonio cultural, tanto de sus bienes culturales materiales como de sus tradiciones y su memoria.

b) Fortalecer la identidad, al brindar nuevas maneras en las que sectores de la comunidad conozcan, interpreten, valoren y disfruten su propia cultura.

d) Mejorar la calidad de vida, ofreciendo diversos tipos de capacitación y generando ingresos a través de la promoción del arte popular y el turismo comunitario.

e) Tender puentes hacia otras comunidades a través del intercambio cultural.

f) Crear redes, propiciando la solidaridad y la creación de proyectos colectivos.

Otras definiciones entienden al museo comunitario como "Una institución que surge de la iniciativa de una comunidad, o parte de ella, a través de un grupo que se constituye en un consejo de vecinos, comité o asociación civil, entre otras formas de organización. La asociación que impulsa el museo determina el tema o historia que se proyecta, responde a los intereses colectivos y alienta la auto-administración de proyectos culturales. La importancia de la creación y funcionamiento de museos impulsados por las organizaciones comunales se basa en el rescate y difusión de la cultura propia, de su patrimonio cultural y natural, a partir de historias locales" (Sepúlveda, 2011) o bien lo entienden como "Un instrumento para resguardar, valorar, dignificar y representar por nosotros mismos nuestro patrimonio cultural, conservando así el alma, voz y cultura de los pueblos autóctonos y marginados de las Américas" (Red Museos Comunitarios de América, 2008).

Para Wells (2006), los museos comunitarios nacen en México y se caracterizan porque la iniciativa nace en la comunidad y es creado y desarrollado con participación comunitaria y administrado por la comunidad. Es un espacio donde la comunidad realiza acciones de adquisición, resguardo, investigación, conservación, catalogación, exhibición y divulgación de su patrimonio cultural y natural para rescatar y proyectar la identidad local fortaleciendo el conocimiento de su proceso histórico a través del espacio y el tiempo" (Wells, 2006).

Es posible observar en estas definiciones algunos patrones comunes en torno al museo comunitario, tales como el rol que cumple la comunidad en él, puesto que es totalmente activa en la generación, mantención, seguimiento de los museos comunitarios, es ella su protagonista; lo cual resulta coherente con las aspiraciones que pretende conseguir este espacio toda vez que busca fomentar la participación, comunicación e integrantes de los actores de la comunidad. Por tanto, sistémicamente los museos comunitarios tienen dos planos de análisis, uno desde la dinámica interna 
de la comunidad, donde pretende mejorar la calidad de vida de sus habitantes, y por otra parte, desde la dinámica externa, genera la posibilidad de intercambios culturales entre distintas realidades comunitarias.

El museo comunitario, se presenta como un espacio donde se pueden dar cita y concreción a lo anteriormente mencionado, transformándose en un centro de gestión cultural, ya que, como lugar de encuentro y diálogo, es un dinamizador del entorno comunitario, siendo la instancia donde convergen los distintos actores culturales y se fomenta la exploración, el descubrimiento, el intercambio intelectual y la sorpresa (Guevara, 2000).

En esta misma línea de argumentación, la DIBAM señala que un museo territorial comunitario puede ser definido como "un espacio donde la comunidad guarda y se encuentra con la memoria de su pasado, con su presente y se proyecta al futuro, siendo un espejo del quehacer (espiritual, social, económico, político y artístico), de las comunidades y lugares donde este patrimonio se resignifica" (DIBAM, 2009)

$\mathrm{Al}$ respecto, la DIBAM señala que los museos territoriales comunitarios forman parte de lo que se ha caracterizado como museos locales, es decir, integrados por la triada comunidad- territorio- patrimonio. Se caracterizan en primer término, por estar establecidos en una territorialidad, que como ya lo hemos definido se plantea como un espacio físico, pero a la vez simbólico, al estar interpretado por la comunidad territorial. Esta línea de trabajo de los museos comunitarios está en directa relación con la denominada "Nueva Museología" la cual:

Es un llamado al cambio (y por ende a la reflexión) de todos los museos contemporáneos; y que no pretende necesariamente la creación de un nuevo tipo de institución sino la transformación de la presente, poniendo énfasis en la función social que todo museo debe cumplir [...] El interés de las instituciones museológicas latinoamericanas, sobre la necesidad de desarrollar los mecanismos que les permita trabajar con la comunidad en la protección del patrimonio y de hacer copartícipes a la comunidad en las políticas y decisiones del museo, ha sido puesto de manifiesto reiteradamente en diversos foros. Desde luego no muy frecuentemente estas expresiones de deseo y compromisos llevados a la práctica, pero sin duda son indicadores de una conciencia institucional sobre esta problemática (DeCarli, G. 2003).

Por ello que, la nueva museología establece ciertos principios rectores de estas iniciativas tales como: democracia cultural, comunidad, territorio, concienciación, sistema abierto e interactivo, diálogo entre sujetos y multidisciplinariedad, la patrimonialización es un proceso estratégico de intervención social y participación sociopolítica porque es un proceso de identificación colectiva (Arrieta, 2007) 
En definitiva, los museos comunitarios constituyen un espacio donde la misma comunidad muestra sus tradiciones, historias y costumbres al resto de la propia localidad y público en general. Esto significa que cada uno de los vecinos aporta con lo que considera que es importante y relevante para él y su grupo familiar, tanto de la historia del pasado como de la actualidad, por tanto, permite que la comunidad se apropie de sus bienes culturales y tome el control de ellos, ya que ayuda a fomentar la cohesión social y reconstruir el tejido social, reforzando los lazos comunitarios, reconstruyendo la historia y mostrando al público en general un discurso que va más allá de la muestra museográfica.

\section{Materiales y método}

La investigación fue desarrollada en el periodo 2016 y 2017 y consistió básicamente en una revisión documental de los museos comunitarios registrados por la Dirección de Bibliotecas Archivos y Museos de Chile. Además, el trabajo de campo se refirió al desarrollo de entrevistas con fundadores y gestores de algunos de ellos, que no estaban incluidos en el registro oficial. El trabajo de investigación consistió también en el desarrollo de un marco conceptual que buscó definir y precisar el concepto de museo comunitario cuyos elementos constituyentes se advierten en proceso de revisión y maduración por parte de los organismos técnicos oficiales.

\section{Análisis y discusión}

\section{Los museos comunitarios en Chile}

Según la DIBAM un museo comunitario es un museo creado por una comunidad, como herramienta para reafirmar su identidad y proteger su patrimonio material e inmaterial. Como puede observarse en anexos, el cuadro 1, es una síntesis descriptiva de los museos comunitarios en Chile de acuerdo a antecedentes extraídos de la fuente oficial de la DIBAM y a información de fuentes secundarias de museos que si bien arrojan que estas expresiones caben en la categoría de comunitarios no están registrados como tales en la oficialidad.

Cuadro 1: Museos Comunitarios en Chile (DIBAM, 2017)

\begin{tabular}{|l|l|c|l|l|l|}
\hline \multicolumn{1}{|c|}{ Museo } & \multicolumn{1}{|c|}{ Misión } & $\begin{array}{c}\text { Año de } \\
\text { inicio }\end{array}$ & $\begin{array}{c}\text { Dependencia } \\
\text { administrativa }\end{array}$ & \multicolumn{1}{c|}{ Origen } & \multicolumn{1}{c|}{ Servicios } \\
\hline $\begin{array}{l}\text { Centro } \\
\text { Cultural } \\
\text { Currarehue }\end{array}$ & $\begin{array}{l}\text { Rescatar y valorizar } \\
\text { las tradiciones y } \\
\text { elementos caracte- } \\
\text { rísticos que configu- } \\
\text { ran la idiosincrasia } \\
\text { de la cultura popular } \\
\text { y tradicional de la } \\
\text { Región del Bío-Bío. }\end{array}$ & 1995 & $\begin{array}{l}\text { Organización } \\
\text { Comunitaria } \\
\text { Funcional... }\end{array}$ & $\begin{array}{l}\text { Guardar, clasificar y conservar } \\
\text { el material poético, musical, } \\
\text { textil, medicina y religiosidad } \\
\text { popular, gastronómica y ar- } \\
\text { tesanal, recolectado desde el } \\
\text { año 1975 por Sylvia Gutiérrez } \\
\text { en la comuna de Sta. Juana y } \\
\text { en otras zonas. }\end{array}$ & $\begin{array}{l}\text { Biblioteca con 660 } \\
\text { libros literatura cos- } \\
\text { tumbrista chilena-his- } \\
\text { panoamericana, enci- } \\
\text { clopedias, arte, historia, } \\
\text { revistas de tejidos, etc. } \\
\text { Colecciones textiles }\end{array}$ \\
\hline
\end{tabular}




\begin{tabular}{|c|c|c|c|c|c|}
\hline Museo & Misión & $\begin{array}{l}\text { Año de } \\
\text { inicio }\end{array}$ & $\begin{array}{l}\text { Dependencia } \\
\text { administrativa }\end{array}$ & Origen & Servicios \\
\hline $\begin{array}{l}\text { Museo de } \\
\text { Farmacia } \\
\text { Dr. César } \\
\text { Leyton }\end{array}$ & $S / I$ & 1951 & $\begin{array}{l}\text { Dependencias } \\
\text { del Colegio } \\
\text { de Químicos } \\
\text { Farmacéuticos, } \\
\text { pero perte- } \\
\text { neciente a } \\
\text { la Facultad } \\
\text { de Ciencias } \\
\text { Químicas y } \\
\text { Farmacéuticas } \\
\text { de la } \\
\text { Universidad de } \\
\text { Chile. }\end{array}$ & $\begin{array}{l}\text { Dar a conocer parte del a his- } \\
\text { toria de la Farmacia en Chile }\end{array}$ & $\begin{array}{l}\text { Presenta equipos, } \\
\text { piezas y materiales y } \\
\text { cerámicas recolectados } \\
\text { a lo largo de los años a } \\
\text { estudiantes y público } \\
\text { en general. }\end{array}$ \\
\hline $\begin{array}{l}\text { Museo } \\
\text { Histórico } \\
\text { Cultural } \\
\text { Antuhuenu }\end{array}$ & $\begin{array}{l}\text { Salvaguardar el } \\
\text { patrimonio cultural, } \\
\text { humano, natural, } \\
\text { de la comuna de } \\
\text { Nacimiento; ya que } \\
\text { desde que se convir- } \\
\text { tió en zona Industrial } \\
\text { ( año 1963) ha sufrido } \\
\text { muchos cambios y } \\
\text { transformaciones } \\
\text { tanto en el área } \\
\text { urbana como rural. }\end{array}$ & 2003 & Privado. & $\begin{array}{l}\text { Busca plasmar la historia de la } \\
\text { ciudad de Nacimiento. }\end{array}$ & $\begin{array}{l}\text { La muestra fotográfi- } \\
\text { ca, es una colección } \\
\text { de imágenes de } \\
\text { Nacimiento antiguo. }\end{array}$ \\
\hline $\begin{array}{l}\text { Museo de } \\
\text { Alhue }\end{array}$ & $\begin{array}{l}\text { El Museo de Alhué } \\
\text { busca proteger y } \\
\text { atesorar el patrimo- } \\
\text { nio cultural material } \\
\text { e inmaterial de la } \\
\text { localidad. }\end{array}$ & 1983 & $\begin{array}{l}\text { Organización } \\
\text { comunitaria. }\end{array}$ & $\begin{array}{l}\text { Intenta poner en valor a im- } \\
\text { portantes personajes y familias } \\
\text { de la zona. representativos de } \\
\text { la vida tradicional. }\end{array}$ & $\begin{array}{l}\text { Presenta objetos anti- } \\
\text { guos colección con más } \\
\text { de } 900 \text { objetos. regis- } \\
\text { tros de matrimonio, } \\
\text { bautizos, nacimientos } \\
\text { y otras inscripciones } \\
\text { desde la fundación de } \\
\text { la parroquia en el siglo } \\
\text { XVIII hasta entrado el } \\
\text { siglo XX. }\end{array}$ \\
\hline
\end{tabular}


CIENCIAS SOCIALES

\begin{tabular}{|c|c|c|c|c|c|}
\hline Museo & Misión & $\begin{array}{c}\text { Año de } \\
\text { inicio }\end{array}$ & $\begin{array}{l}\text { Dependencia } \\
\text { administrativa }\end{array}$ & Origen & Servicios \\
\hline $\begin{array}{l}\text { Museo de } \\
\text { la Vivencia } \\
\text { Religiosa } \\
\text { del Norte } \\
\text { Grande }\end{array}$ & $\begin{array}{l}\text { Busca contribuir a } \\
\text { fortalecer la iden- } \\
\text { tidad religiosa del } \\
\text { hombre y de la } \\
\text { mujer del norte } \\
\text { grande de chile, } \\
\text { actuando como un } \\
\text { foco que permita } \\
\text { la generación en la } \\
\text { comunidad de la au- } \\
\text { toconciencia de su } \\
\text { identidad, con el fin } \\
\text { de valorar, conservar, } \\
\text { proteger, desarrollar } \\
\text { y transmitir su patri- } \\
\text { monio en vincula- } \\
\text { ción armónica a la } \\
\text { tradición. }\end{array}$ & 2015 & Iglesia. & $\begin{array}{l}\text { Busca mostrar la identidad } \\
\text { religiosa del norte grande y } \\
\text { las diferentes expresiones de } \\
\text { fe y cultura que se entrelazan } \\
\text { en estas desérticas tierras del } \\
\text { norte de Chile. }\end{array}$ & $\begin{array}{l}\text { Cuenta con diversas } \\
\text { piezas donadas por la } \\
\text { comunidad. }\end{array}$ \\
\hline $\begin{array}{l}\text { *Museo } \\
\text { Barrio } \\
\text { Yungay }\end{array}$ & $\begin{array}{l}\text { Busca contar la } \\
\text { vida del barrio y de } \\
\text { sus residentes con } \\
\text { fotografías, cartas, } \\
\text { muebles y otras per- } \\
\text { tenencias que han } \\
\text { sido donadas por los } \\
\text { mismos vecinos. }\end{array}$ & 2015 & $\begin{array}{l}\text { Organización } \\
\text { comunitaria } \\
\text { Funcional. }\end{array}$ & $\begin{array}{l}\text { Su objetivo es recuperar la } \\
\text { memoria del territorio, y que } \\
\text { las personas conozcan la vida } \\
\text { e historia que existe en la zona. }\end{array}$ & $\begin{array}{l}\text { Presenta Fotografías, } \\
\text { cartas, muebles y otras } \\
\text { pertenencias, el museo } \\
\text { busca rescatar la histo- } \\
\text { ria del barrio y de sus } \\
\text { residentes. }\end{array}$ \\
\hline $\begin{array}{l}\text { *Museo } \\
\text { Histórico de } \\
\text { Placilla } 2009\end{array}$ & $\begin{array}{l}\text { Preservar, investigar, } \\
\text { promover, valorizar, } \\
\text { sensibilizar y divulgar } \\
\text { el patrimonio que } \\
\text { posee Placilla de } \\
\text { Peñuelas y su rela- } \\
\text { ción con la ciudad } \\
\text { de Valparaíso, la } \\
\text { Región y el país. }\end{array}$ & 2009 & $\begin{array}{l}\text { Organización } \\
\text { comunitaria } \\
\text { Funcional. } \\
\text { El Centro } \\
\text { Cultural Placilla } \\
\text { (CCP) es una } \\
\text { organización } \\
\text { social sin fines } \\
\text { de lucro. }\end{array}$ & $\begin{array}{l}\text { Busca recordar a los vecinos } \\
\text { las más cruentas batallas de la } \\
\text { Guerra Civil en agosto de } 1891 .\end{array}$ & $\begin{array}{l}\text { Alberga objetos que los } \\
\text { vecinos fueron encon- } \\
\text { trando de niños, como } \\
\text { por ejemplo tesoros } \\
\text { que pertenecieron a } \\
\text { otras épocas. }\end{array}$ \\
\hline
\end{tabular}

El Cuadro 1, presenta la situación de siete museos chilenos en la clasificación de museos comunitarios. Cinco de ellos están registrados en los datos oficiales de la DIBAM, organismo estatal encargado de proteger y registrar el patrimonio nacional pero también de ir registrando estas nuevas manifestaciones culturales que emergen en este caso de la propia comunidad, aunque en algunos casos como se aprecia en el cuadro sean resultado de acciones o iniciativas más bien institucionales como es el caso del Museo de Farmacia asociado a la Universidad de Chile, que más bien estaría asociada a la preservación de una comunidad de carácter "funcional" que "territorial", como ocurre con todos los demás. 
Por otra parte, llama la atención que gran parte de estos museos comunitarios (cuatro de siete) hayan iniciado sus actividades de conservación a partir del año 2000 lo que estaría asociado con una respuesta sociocultural comunitaria a estas nuevas configuraciones asociadas a la recuperación de la identidad en épocas de globalización como lo señala Castells. Esto sin duda marca una tendencia creciente de interés museológico al cual se debe estar atento ya sea para promoverlos o bien facilitar su desarrollo, aun cuando se entiende que deben estar orientados por definición a intereses genuinos y autónomos de la comunidad.

Es importante desatacar que sólo cuatro museos de este cuadro son efectivamente organizaciones comunitarias funcionales y el resto representan instituciones estrictamente privadas lo que generaría cierta tensión con las definiciones de museo comunitario presentadas al inicio de este artículo. Esto debiera considerarse con las instituciones estatales que registran el desarrollo museológico a nivel nacional.

Finalmente, cabe destacarse que la Ley 19.418 sobre Juntas de Vecinos y otras organizaciones comunitarias facilita la constitución de organizaciones funcionales donde los vecinos se agrupen y asocien en virtud de un interés común y no necesariamente con énfasis territorial como lo son las juntas de vecinos, aun cuando en este caso lo funcional se justificaría por la expresión de territorialidad patrimonial que significa este tipo de expresiones museológicas. En este sentido esta ley pudiera transformarse en una herramienta efectiva en la consolidación de estos espacios de participación comunitaria.

\section{Conclusiones}

Los Museos Comunitarios aportan indudablemente en Chile al desarrollo sostenible y a la calidad de vida de la comunidades donde se insertan, ya que ésta es comprendida como un fenómeno multidimensional que integra aspectos tanto internos (individuo) como externos (medio social), "ambas dimensiones ponen de manifiesto la importancia de elementos sociales, contextuales, para la construcción de la calidad de vida de sujeto, poniendo de relieve el conjunto social y cultural del cual forma parte" (Gatica, 2014)

Lo anterior, fortalece la necesidad de investigar a nivel micro social el desarrollo, constitución, y dirección que adoptan las comunidades en su proceso evolutivo, donde justamente se releva la importancia de conocer, integrar y comprender nuestros antecedentes históricos como seres sociales, cuestión que en ocasiones potencia el arraigo, identidad y pertenencia a nuestros territorios. Los objetivos del Desarrollo Sostenible de la agenda 2030 nos obliga no solo a propender a generar ciudades y comunidades sostenibles sino además a reducir las desigualdades de todo tipo, incluso las asociadas al ejercicio de asimetrías de poder entre los distintos grupos que cohabitan un territorio, y en este sentido las promociones de este tipo de expresiones museológicas están en esa dirección. La generación de museos comunitarios también 


\section{CIENCIAS SOCIALES}

ayuda a gestar cuotas de paz y justicia en nuestras comunidades sumándose a otro tipo de acciones democráticas en ese sentido.

Refuerza lo anterior: La museología debe ampliar sus objetivos, más allá de su papel y funciones tradicionales de identificación, conservación y educación, para que su acción pueda incidir mejor en el entorno humano y físico... la museología recurre cada vez más a la interdisciplinariedad.... a nuevos métodos de gestión capaces de integrar a los usuarios...preservando los hallazgos materiales de civilizaciones pasadas, protegiendo aquellos que son testimonio de las aspiraciones y de la tecnología actual, la nueva museología - eco-museología, museología comunitaria y otras formas de museología activa - se interesa, en primer lugar, por el desarrollo de los pueblos, reflejando los principios de su evolución y asociándolos a los proyectos de futuro (Declaración de Quebec, 1984).

Se trata de generar encuentros vecinales-barriales que involucren el conocer el lugar donde se habita, que permita construir relatos y discursos respecto de identidad comunitaria desde los propios habitantes, que permita reconocer los patrimonios locales, que permita fortalecer los valores comunitarios (muchas veces implícitos), es así, que el museo comunitario se presenta como "Un espacio donde se pueden dar cita y concreción a lo anteriormente mencionado, transformándose en un centro de gestión cultural, ya que como lugar de encuentro y diálogo, es un dinamizador del entorno comunitario, siendo la instancia donde convergen los distintos actores culturales y se fomenta la exploración, el descubrimiento, el intercambio intelectual y la sorpresa (Guevara, 2001). De este modo, la propia comunidad muestra sus tradiciones, historias y costumbres al resto de la propia localidad y público en general, lo cual implica que cada uno de los vecinos aporta con lo que significa como importante tanto de la historia del pasado como del presente y respecto del futuro la actualidad. "El Museo Comunitario es la vida de un pueblo donde plasmamos nuestro pasado y dejamos huella a las futuras generaciones" (Camarena y Morales, 2009). También, se debe señalar al respecto que, en el campo de las Ciencias Sociales, existe un escaso interés por la museología y la utilización de su metodología como herramienta de construcción social, más aún, el espacio museo aún carece de mostrar su real magnitud social, toda vez, que los museos se definen como espacios abiertos donde pueden y deben ejercer una función de importancia en la sociedad, y vinculados de la mejor manera, a su territorio y su comunidad (Wells, 2006).

En definitiva, se presenta una gran oportunidad desde la academia y desde las políticas públicas inclusivas, equitativas y multiculturales para aportar al bienestar de los barrios, desde el conocimiento, investigación y divulgación de estos proyectos micro sociales que emergen desde los propios espacios locales como una alternativa para generar sustentabilidad, identidad y valor patrimonial de su pasado, presente y futuro. 


\section{Lista de referencias}

Aneas Álvarez, M. A (2005). Competencia intercultural, concepto, efectos e implicaciones en el ejercicio de la Ciudadanía. Revista Iberoamericana de Educación, Vol. 36 Núm. 13 (ISSN: 1681-5653).

Arrieta, I. (2007). Participación Ciudadana, Patrimonio Cultural y Museos. Servicio Editorial de la Universidad del país Vasc Euskal Herriko Unibersitateko Argitalpen Zerbitzua.

Bartolomé, M. (2004). Educación intercultural y ciudadanía. En Grañeras. La formación del profesorado en educación Intercultural. 93-122. Madrid. La Catarata.

BID (2000). Pobreza en áreas centrales urbanas Métodos de análisis e intervenciones Manual de consulta para profesionales. Francesco Lanzafame y Alessandra Quartesan (Editores)

Bourdieau, P. (1999). Intelectuales, política y poder. Buenos Aires, Eudeb.

Castells, M. (2003) Estado, Sociedad y Cultura en la globalización de América Latina con referencia a la especificidad chilena. Documento presentado al Foro de Altos Estudios Valparaíso.

Decarli, G. (2003). Vigencia de la Nueva Museología en América Latina: Conceptos y Modelos". Revista ABRA de la Facultad de Ciencias Sociales de la Universidad Nacional, Editorial EUNA, Costa Rica.

Francesco Lanzafame y Alessandra Quartesan (Editores, 2009). Pobreza en áreas centrales urbanas Métodos de análisis e intervenciones Manual de consulta para profesionales.

Gatica, K. (2014). Aproximación al estudio y Comprensión de la Calidad de Vida. Documento de Trabajo, Facultad Ciencias Humanas y Educación, Universidad del Pacífico, Santiago de Chile. No Publicado.

Guevara, A. 200o. El Museo Comunitario como Fortalecedor de la Identidad y Desarrollo Local. IV Congreso Chileno de Antropología, Colegio de Antropólogos de Chile A. G, Santiago de Chile.

Morales, T, y Camarena, C. (2009). Manual para la creación y desarrollo de museos comunitarios. Fundación interamericana de cultura y desarrollo (ICDF). 
ONU - Habitat (2012). Estado de las Ciudades de América Latina y El Caribe 2012. Rumbo a una nueva transición urbana Programa de las Naciones Unidas para los Asentamientos Humanos.

Sepúlveda T, (2011). Museología y comunalidad. Una aproximación al estudio de los museos comunitarios de Oaxaca. Trabajo final de investigación no publicado, Master en Gestió del Patrimoni Cultural, Facultat de Geografia e Historia, Universidad de Barcelona, España

Wells, C. (2006). Hacia la construcción de Museos Comunitarios: Fundamentos para un Museo Territorial Comunitario en el lafkenmapu, Comuna de Valdivia. X región. Tesis para optar a título de Antropóloga y al grado de licenciada en Antropología, Facultad de Filosofía y Humanidades Instituto de Ciencias Sociales, Escuela de Antropología, Valdivia, Chile. 